\title{
Construction of Innovation and Entrepreneurship Platform for Vehicle Engineering under the Background of New Engineering Education
}

\author{
Shanshan Guo \\ School of Mechanical-electronic and Vehicle Engineering \\ Weifang University \\ Weifang, Shandong, China \\ Lucy001478@163.com
}

\author{
Yongsheng Liu \\ School of Mechanical-electronic and Vehicle Engineering \\ Weifang University \\ Weifang, Shandong, China
}

\begin{abstract}
In view of the traditional teaching system of automobile engineering innovation and entrepreneurship, there are many problems such as poor student ability and weak innovation consciousness. Under the background of new engineering, the 136 teaching system of innovation and entrepreneurship with the vehicle engineering talents as the core was constructed. The system has been reformed in terms of innovative experimental platform construction, innovative projects, the building of education team and evaluation systems. The results show that the reformed experimental teaching system pays attention to the teaching atmosphere led by students and teachers, highlights the students' ability to quickly adapt to the regional power machinery and new energy automobile industry, and enhance the entrepreneurial ability of new engineering innovative talents. Meantime, practice ability and innovation quality have a good reference for improving the quality of innovative talents.
\end{abstract}

Keywords-Innovation and Entrepreneurship Platform; New engineering; Experimental platform construction; Evaluation system

\section{INTRODUCTION}

Emerging engineering education (3E) is the direction of engineering education reform in China, which is based on the new needs of national strategic development, the new situation of international competition and the new requirements of moral education. The connotation of the new subject is to cultivate future diversified and innovative engineering talents with the characteristics of strategy, innovation, systematization and openness, guided by moral education, taking coping with changes and shaping the future as the construction concept, inheriting and innovating, crossing and integrating, coordinating and sharing as the main ways [1].

The innovation and entrepreneurship education of college students is a comprehensive and systematic education with the main content system of cultivating innovation ability, entrepreneurial awareness and spirit, improving innovation and entrepreneurial knowledge and ability, and strengthening guidance on innovation and entrepreneurship practice activities. To promote the sustainable and healthy development of innovation and entrepreneurship education, we should establish a complete entrepreneurial and entrepreneurial education system, reform the talent training model, and build a mode of operation with students as the mainstay, college teachers as the guides, and enterprises as the participants. To form a new mechanism for talents training in innovation and entrepreneurship, we must also strengthen the construction of an innovation and entrepreneurship education platform, encourage university students' innovation and entrepreneurial activities, and increase investment in project funding and innovation environment for college students' innovation and entrepreneurship, and form a good study. And the cultural atmosphere is to cultivate a complex talent with innovative entrepreneurship [2].

\section{THE CONSTRUCTION OF INNOVATION AND ENTREPRENEURSHIP PLATFORM}

Adhere to the orientation of serving local economy and the goal of training high-quality applied engineering technicians [3]. Taking innovation and entrepreneurship training as the core, we integrate the existing innovation laboratories and teaching style, research projects on the basis of experimental teaching platform and engineering training platform, and build an experimental platform for scientific and technological innovation. As shown in Fig.1[4].

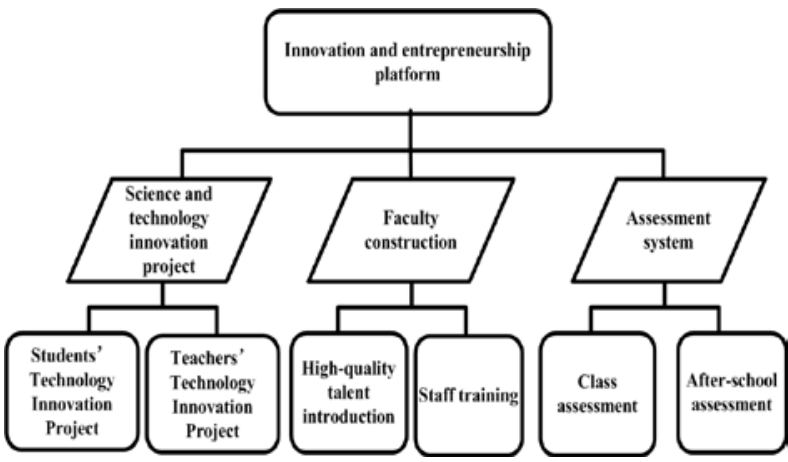

Fig. 1 Construction of Innovation and entrepreneurship platform

\section{PlatFORM FOR SCIENTIFIC AND TECHNOLOGICAL INNOVATION}

It mainly includes students' science and technology innovation project and teachers' innovation project. Reorganization of existing innovation laboratories, construction of student-centered student science and 
technology innovation project center, relying on innovation contest, innovation laboratory and University Students' entrepreneurship project, and problem solving-oriented, vigorously promote and encourage students to participate in science and technology innovation projects, such as university smart car contest, electromechanical design contest, carbonfree car contest, ISTP innovation and entrepreneurship activities, to provide science and technology. Innovation of experimental sites, experimental funds, simplification of reimbursement procedures, provision of instructors, extensive application of technology research and scientific and technological services, to enhance students' independent thinking, dynamic practice and innovation ability[5].

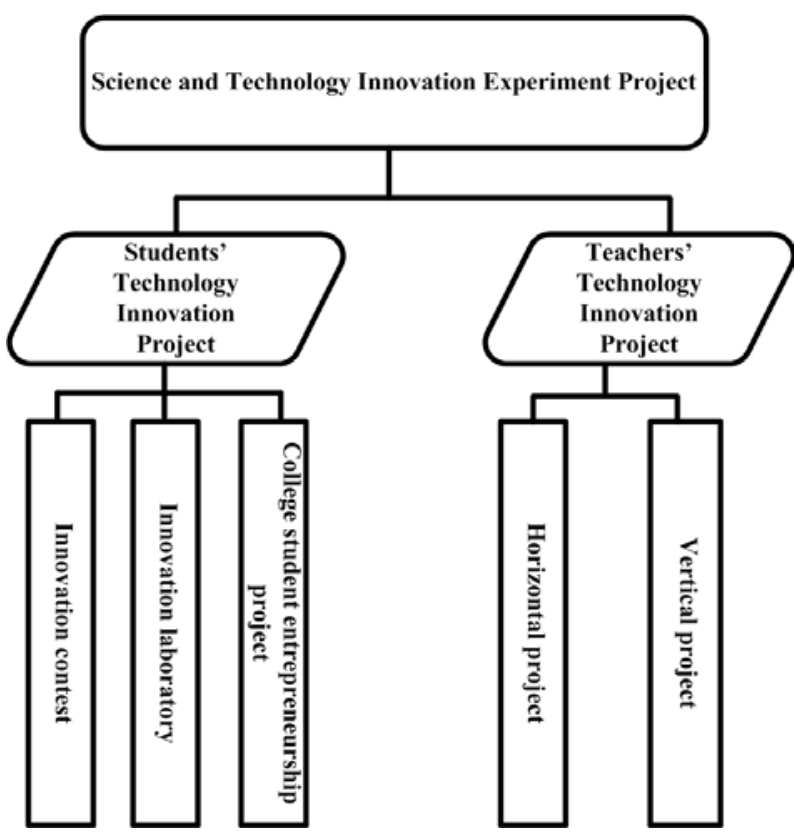

Fig. 2 Science and Technology Innovation Experiment Project

As shown in Fig.2, construction of Teacher Innovation Project Center, divided into horizontal and vertical projects, encourages students to log on to network experimental teaching platform [6], view full-time teachers' educational and research projects, online self-learning, active participation, exercise their extracurricular technological innovation and engineering design capabilities, and support and encourage teachers, students and enterprises to jointly develop new products. New technology, exercise engineering consciousness and practical ability, improve engineering application design and scientific and technological innovation ability, and improve social service ability.

\section{DIVERSIFIED TEACHER TEAM CONSTRUCTION}

In order to strengthen the construction of teaching staff and improve the practical teaching ability of teachers, relying on the regional advantages of Weifang Dynamics City, we should actively explore the construction of diversified teaching staff, strengthen the interdisciplinary integration [7], implement the two-way communication mechanism between school and enterprise personnel, and appoint teachers to high-level academic teams, well-known universities, well-known enterprises and institutions. Vocational training; a large number of high-level talents are introduced from well-known universities and well-known enterprises and employed as experts both inside and outside the school. We will continue to promote the "double-qualified" teaching staff construction model of the vehicle professional group and build a professional teaching team with rich theoretical knowledge and skilled practical skills [8].

As shown in Fig. 3, there are 31 full-time teachers in this specialty, including 3 professors and 15 associate professors, accounting for $58.1 \%$ of the total number of teachers; 17 teachers under 45 years of age, including 13 teachers with doctoral degrees, accounting for 55\% and 42\% respectively; 3 backbone teachers in Weifang university and 17 double-type teachers, accounting for $54.8 \%$. Three tutors of part-time master's degree students, 10 part-time teachers with senior professional titles were recruited from universities and automobile industry enterprises in the province, and a team of teachers with reasonable educational background, age and professional title structure was formed. 


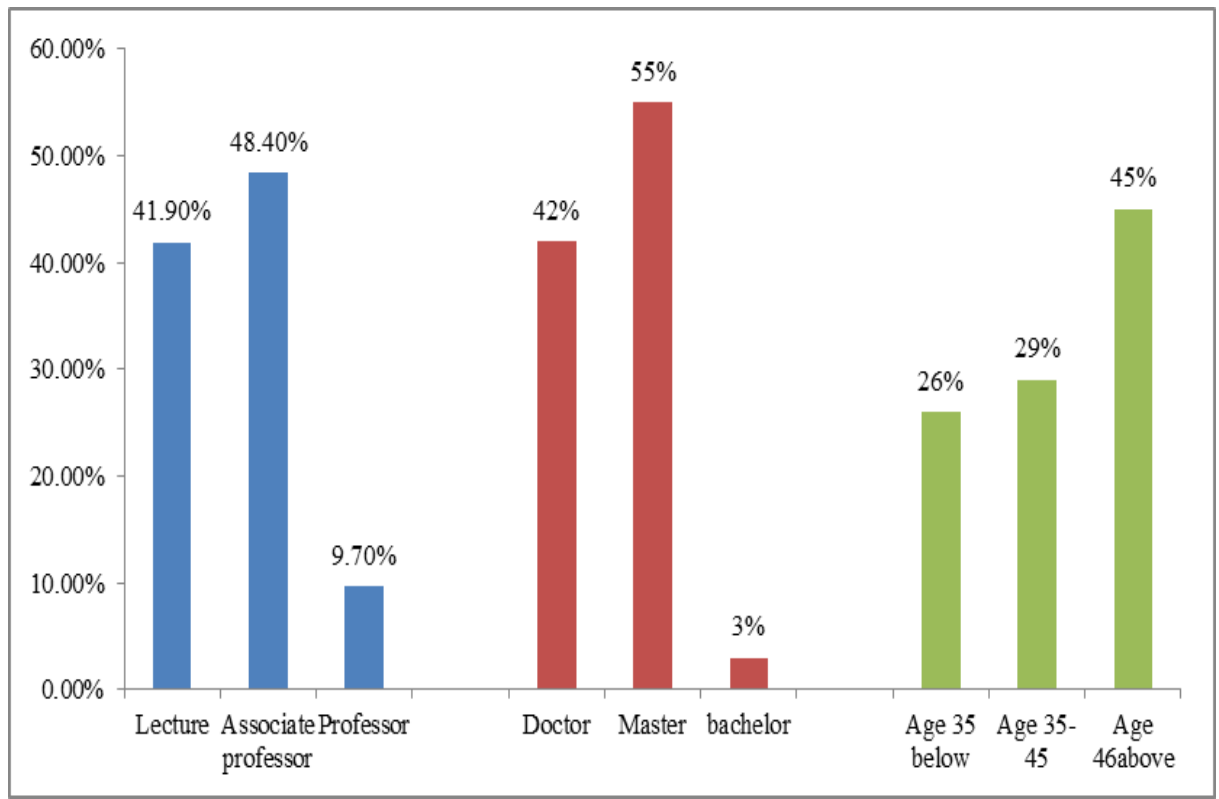

Fig. 3 Teacher team construction

\section{Establishment OF MUlTi-INDEX AND PHASED ASSESSMENT SYSTEM}

To improve the experimental ability of the major as the core target combined with the characteristics of the students of this major, a multi-index phased assessment system is established, as shown in Fig. 4. Drawing on the experience and achievements of outstanding engineers in core majors, the preclass preview, classroom performance and homework of the experimental courses are assessed at different stages, and the specific assessment level is appropriately mastered by the teachers. Strengthen the process assessment, and carry out multi-index process assessment on attendance, experimental performance, experimental report, team awareness, small papers, etc.[9].

In order to remedy the problems existing in the previous evaluation system, such as the emphasis on results, the neglect of process, the lack of comprehensiveness of student evaluation, and the incompleteness of assessment and evaluation, etc., so as to strengthen the cultivation of practice and practical ability, team cooperation and innovation consciousness.

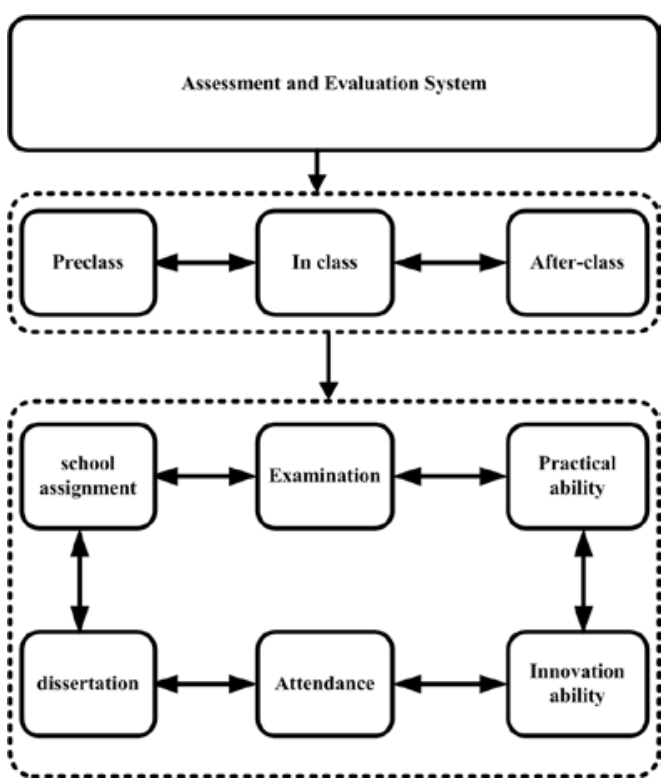

Fig. 4 Assessment and Evaluation System

\section{CONCLUSION}

The innovative entrepreneurship teaching platform for vehicle engineering specialty based on the background of new subjects integrates the advantages of campus, school enterprises and campus resources, and integrates the project platform, teacher platform and evaluation system of innovative entrepreneurship teaching into an organic whole.

Through the organic combination of the three platforms, the aim is to train students' innovative entrepreneurship as the main line, focusing on conception, design and reality. Training in gymnastics and innovation can fully mobilize students' subjective initiative, cultivate students' ability to think actively, learn independently and solve problems independently, stimulate students' engineering ability and innovative 
consciousness, and achieve ideal results. This is also part of the implementation of the "Excellent Engineer Training Plan" for Vehicle Engineering Major, which promotes the innovation of similar engineering majors. The quality of entrepreneurship training has certain reference and promotion value.

\section{ACKNOWLEDGMENT}

This work was supported in part by Ministry of Education Collaborative Education Project

(201802105006, 201801245026), Shandong Provincial Higher Education Science and Technology Plan Project (J18kA012, J16LB10, and J17KA150); Weifang Science and Technology Development Plan Project (Grant No.2019GX013).

\section{REFERENCES}

[1] Zhong Denghua. Connotation and Action of New Science Construction [J]. Research on Higher Engineering Education, 2017 (03): 7-12.

[2] Cao Jianhui, Zhou Hebing, Luo Yifan. Innovation and entrepreneurship education model for college students [J]. Laboratory research and exploration, 2010 (8): 195-198.

[3] Nian Qingang, Liao Qingmin. Construction of Innovative Talents Training and Experimental Teaching Demonstration Center [J]. Laboratory Research and Exploration, 2010, 29 (9): 116-118.
[4] Bi Ying, Yang Liansheng. Essence and Policy Suggestions of Collaborative Innovation of Interdisciplinary Research Organizations in Universities [J]. Research on Educational Development, 2014 (9): 34-39.

[5] Jiang Zhoushu, Xu Hanghui, Fanbing, the standardization construction and information service of chemical reagent Library in Colleges and universities [J]. Experimental technology and management, 2018, 35 (11): 1-5.

[6] Shen Yunci. An analysis of the risk index system of collaborative innovation of industry, University and research [J]. Education Development Research, 2014 (9): 46-51.

[7] Luo Pinjie. Construction and Exploration of Laboratory Management Center in Applied Undergraduate Colleges [J]. Laboratory Research and Exploration, 2016, 35 (6): 254-257.

[8] Chen Peng, Li Ya, Ji Jing. Practice and Exploration of Innovative Experimental Program for College Students Relying on Experimental Course [J]. Experimental Technology and Management, 2014, 31 (4): 32-34.

[9] Liu Yunlong, Tang Shuhong, Kao Yonggui, Ji Tao, Gao Yourui, Wu Xiaojin. Active project teaching method for modern control system course [J]. Laboratory research and exploration, 2016, 35 (1): 161-165.

[10] Ni Jianwei. Characteristic construction of key disciplines in Local Universities Based on regional development [J]. Research on educational development, 2014 (9): 15-19.

[11] $\mathrm{Xu} \mathrm{Xin}, \mathrm{Zhu}$ Jianjun, Zhao Chunfeng. [J] Engineering Training Teaching Reform of "Education and Training Plan for Excellent Engineers". Laboratory Research and Exploration, 2014 (33): 223-226. 